\title{
The Current State of Palliative Care for Patients Cared for at Leading US Cancer Centers: The 2015 NCCN Palliative Care Survey
}

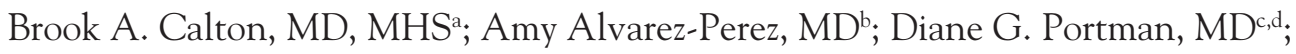 \\ Kavitha J. Ramchandran, MDi ; Jessica Sugalski, MPPA f and Michael W. Rabow, MDg
}

\begin{abstract}
Background: ASCO and IOM recommend palliative care (PC) across health care settings for patients with serious illnesses, including cancer. This study provides an overview of the current availability, structure, and basic quality of PC services within NCCN Member Institutions. Methods: A PC survey was developed by NCCN staff and a working group of PC experts from 11 NCCN Member Institutions under the auspices of the NCCN Best Practices Committee. The survey was piloted and refined by 3 working group members and sent electronically to all 26 NCCN Member Institutions. NCCN staff and working group leaders analyzed the survey data. Results: A total of 22 of 26 institutions responded (85\%). All respondents (100\%) reported an inpatient PC consult service (staffed by an average of 6.8 full-time equivalents [FTEs], seeing 1,031 consults/year with an average length of stay [LOS] of 10 days). A total of $91 \%$ of respondents had clinic-based PC (with an average of 469 consults/year, staffed by an average of $6.8 \mathrm{FTEs}$, and a 17-day wait time). For clinics, a comanagement care delivery model was more common than strict consultation. Home-based PC (23\%) and inpatient PC units (32\%) were less prevalent. Notably, $80 \%$ of institutions reported insufficient PC capacity compared with demand. Across PC settings, referrals for patients with solid tumors were more common than for hematologic malignancies. Automatic or "triggered" referrals were rare. The most common services provided were symptom management (100\%) and advance care planning (96\%). Most programs were funded through fee-for-service billing and institutional support. Partnerships with accountable care organizations and bundled payment arrangements were infrequent. PC program data collection and institutional funding for PC research were variable across institutions. Conclusions: Despite the prevalence of PC inpatient and clinic services among participating NCCN Member Institutions, PC demand still exceeds capacity. Opportunities exist for expansion of home-based PC and inpatient PC units, optimizing referrals, research, and payer collaborations.
\end{abstract}

J Natl Compr Canc Netw 2016;14(7):859-866

\section{Background}

As data on the benefits of palliative care (PC) for patients with cancer accumulate, ${ }^{1-5}$ models for integrating $\mathrm{PC}$ into cancer centers have been proposed. ${ }^{6} \mathrm{Led}$ by ASCO, the Commission on Cancer, and IOM, ${ }^{7-10}$ prominent professional organizations now recommend PC be integrated routinely into cancer care, particularly for patients with advanced disease. NCCN, an alliance of leading US cancer centers, features a clinical guide-

From a Division of Geriatrics, UCSF, San Francisco, California; 'D Department of Supportive and Palliative Care, Roswell Park Cancer Institute, Buffalo, New York; 'Supportive Care Medicine, Moffitt Cancer Center, and dUniversity of South Florida, Tampa, Florida; eStanford Cancer Institute, Stanford, California; ${ }^{f}$ National Comprehensive Cancer Network, Fort Washington, Pennsylvania; and ${ }^{2}$ UCSF Helen Diller Family Comprehensive Cancer Center, San Francisco, California.

Submitted December 9, 2015; accepted for publication March 25, 2016. line on PC for patients with cancer and includes PC recommendations in other clinical guidelines. ${ }^{11}$

Numerous studies suggest penetration and capacity of PC services, both inpatient and in the community, have not kept pace with recommendations, including for patients with cancer. ${ }^{12-17}$ Hui et $\mathrm{al}^{12}$ surveyed cancer centers in 2010 and found inpatient PC services in 91\% of NCI-designated comprehensive cancer centers and outpatient services in 59\%. Prevalence in non-NCIdesignated centers was much lower (56\% inpatient and

The authors have disclosed that they have no financial interests, arrangements, affiliations, or commercial interests with the manufacturers of any products discussed in this article or their competitors.

Correspondence: Brook A. Calton, MD, MHS, University of California, San Francisco, 3333 California Street, Suite 380, San Francisco, CA 94118. E-mail: brook.calton@ucsf.edu 
$22 \%$ outpatient). In another study, $55 \%$ of patients seen at a comprehensive cancer center did not receive PC before death. ${ }^{18}$ No recent research has assessed adherence to recommendations for universal availability of $\mathrm{PC}$ for patients with advanced cancer.

Numerous organizations have recommended metrics to assess the quality of PC provided. ${ }^{19-21}$ However, data about the quality of PC provided to patients with cancer are limited, and much of these data are from single institutions. ${ }^{5,22-24}$

To examine the current availability and basic quality of PC services for US patients with cancer, we surveyed NCCN Member Institutions regarding the prevalence, type, staffing, and financing of their PC programs. We also inquired about metrics, research, and education within their PC programs.

\section{Methods}

The NCCN Best Practices Committee (BPC) provides a forum for senior physician and administrative leaders from NCCN Member Institutions to collaborate, network, and share strategies aimed towards improving the effectiveness and efficiency of cancer center operations. The NCCN BPC promotes research studies for the purpose of benchmarking, determining best practices, and performance improvement. Each NCCN Member Institution appoints one representative to serve on the NCCN BPC.

The 2015 NCCN Palliative Care Survey was developed by NCCN staff with a working group of PC experts from 11 NCCN Member Institutions. The 2015 survey expanded on an initial BPC 2014 survey regarding $\mathrm{PC}$ programs. Working group members (WGMs; see supplemental eAppendix 1, available with this article at JNCCN.org) developed an extensive list of potential survey questions that could provide valuable data to PC and cancer center leaders. To develop the 2015 survey, WGM individually ranked the importance of each potential survey question on a 5-point scale. The first draft was piloted by 3 WGMs. The survey was revised based on their feedback and a second pilot was conducted with the same 3 WGMs. In April 2015, the final survey (see supplemental eAppendix 2) was sent electronically to all 26 NCCN Member Institutions with a request to complete the survey within 4 weeks. A reminder email was sent if no response was received after 4 weeks. The PC survey was sent to the NCCN BPC with instructions to forward the survey to the staff most knowledgeable about that institution's PC services.

Survey data were analyzed jointly by NCCN staff and working group co-leaders (B.A.C. and M.W.R.) using descriptive statistics and group $t$-tests, without between-group comparisons. Statistical significance was a $P$ value less than 0.05 . Because the survey did not include patient-specific data and was intended for quality improvement purposes, the study was exempted from Institutional Review Board review from UCSF's Committee on Human Research.

\section{Results}

\section{Response Rate}

Of the 26 NCCN Member Institutions, 22 responded to the survey ( $85 \%$ response rate; see supplemental eAppendix 3).

\section{Program Structure}

The basic program structure is described in Table 1 . Each institution reported an inpatient PC consultation service. The inpatient PC consultation programs were established between 1991 and 2012, with three-quarters beginning after 2005. An outpatient clinic established between 1981 and 2013 was reported by 20 institutions (91\%), with three-quarters established in the last 10 years. A comanagement care delivery model ( $85 \%$ of clinics reported they do at least some comanagement) was more common than strict consultation (48\% of clinics reported they do at least some consultation). For the purpose of this study, comanagement is defined as having PC providers actively prescribe and enact $\mathrm{PC}$ treatment plans alongside the patient's oncology team (concurrent with the oncologists' care), whereas strict consultation is providing treatment recommendations that the oncology team can then decide to enact. Inpatient PC or hospice units (32\%) and home-based PC or mobile PC programs (23\%) were less prevalent. Most inpatient PC or hospice units and homebased PC programs were established in 2010 or later.

Across PC settings, referrals for patients with solid tumors were more common than for those with hematologic malignancies. Of the 22 institutions responding, $17(77.2 \%)$ reported that more than half of their referrals were for patients with solid tumors. In order of prevalence, patients with gastrointestinal cancers, thoracic cancers, breast cancers, and 


\begin{tabular}{|c|c|}
\hline Characteristic & $\begin{array}{l}\% \text { Answered Yes } \\
\text { (Number of } \\
\text { Respondents) }\end{array}$ \\
\hline \multicolumn{2}{|l|}{ Palliative care service available } \\
\hline Inpatient consultation & $100(22 / 22)$ \\
\hline Clinic & $91(20 / 22)$ \\
\hline Inpatient unit or hospice & $32(7 / 22)$ \\
\hline Home-based/mobile & $23(5 / 22)$ \\
\hline \multicolumn{2}{|c|}{$\begin{array}{l}\text { Referrals of patients with solid tumors (vs hematologic } \\
\text { malignancies) }\end{array}$} \\
\hline$<10 \%$ & $0(0 / 21)$ \\
\hline $10 \%-24 \%$ & $10(2 / 21)$ \\
\hline $25 \%-49 \%$ & $10(2 / 21)$ \\
\hline $50 \%-75 \%$ & $33(7 / 21)$ \\
\hline$\geq 75 \%$ & $47(10 / 21)$ \\
\hline \multicolumn{2}{|c|}{ Automatic or "triggered" referrals } \\
\hline Inpatient consult & $14(3 / 22)$ \\
\hline Clinic & $20(4 / 20)$ \\
\hline Home & $20(1 / 5)$ \\
\hline \multicolumn{2}{|l|}{ Services provided } \\
\hline Symptom management & $100(22 / 22)$ \\
\hline Advance care planning & $96(21 / 22)$ \\
\hline Bereavement services & $64(14 / 22)$ \\
\hline Psycho-oncology & $68(15 / 22)$ \\
\hline Survivorship support & $59(13 / 22)$ \\
\hline Child-life services & $50(11 / 22)$ \\
\hline
\end{tabular}

hematologic malignancies were most often referred for inpatient PC consultation. Patients referred for outpatient PC services most often had diagnoses of gastrointestinal, breast, or thoracic cancers, followed by hematologic malignancies.

Automatic or "triggered" referrals were rare. Only 3 of 22 inpatient consultation programs (13.6\%) and 4 of 22 outpatient clinic programs $(18.2 \%)$ reported a mechanism for automatic referrals. Several programs cited a lack of PC capacity as an explanation for avoiding automatic referrals.

The most frequently perceived barriers to optimal PC referrals by oncologists were unfamiliarity with the scope of $\mathrm{PC}$ services, the perception that $\mathrm{PC}$ is already delivered in their own oncology clinics, and late PC referrals.

Across PC settings, our findings showed symptom management and advance care planning services were nearly universal. The availability of other services, including psycho-oncology, child life services, bereavement services, and survivorship support, was more variable (Table 1 ).

\section{Program Staffing, Demand, and Financing}

Across PC settings, the mean $+/$ - standard deviation for physician and nurse practitioner full-time equivalent (FTE) staffing was $4.1+/-2.9$ and $2.8+/-2.0$, respectively. Nearly all institutions reported chaplain (mean FTE, $0.9+/-0.9$ ) and social work (mean FTE, $3.3+/-5.6$ ) support. Most programs also had nursing support (mean FTE, $1.6+/-1.5$ ). Notably, $80 \%$ of institutions reported insufficient PC capacity compared with demand.

Most programs were funded through fee-for-service billing and institutional support. Risk-based reimbursement methodologies (ie, Accountable Care Organization arrangements, global reimbursement, bundled payments) were rare. Roughly half (52\%) of the institutions' PC programs covered the salaries of nonbilling providers.

Inpatient PC consultation staffing is described in Table 2. Inpatient consult services were staffed by an average of 6.8 FTEs (billing and nonbilling providers). They saw an average of 1,032 +/- 557 unique consults per year (151.8 consults/FTE annually). The average length of stay on the consult service was 10 days.

Clinic-based PC staffing is described in Table 3. PC clinics saw an average of $469+/-215$ unique patients per year with an average staffing of 3.3 FTEs (142.1 new patients per FTE annually). Clinic visits were conducted by a mix of physicians and advance practice providers (APPs). A total of $19 \%$ of institutions reported clinic visits conducted by physicians only, $43 \%$ conducted jointly by both physicians and APPs, 10\% by APPs only, and 29\% listed "other" (including nurse visits, new visits with physician,

\begin{tabular}{|lc|}
\hline \begin{tabular}{|} 
Table 2. Inpatient Palliative Care Consultation \\
Characteristics
\end{tabular} \\
\hline Characteristic & $\begin{array}{l}\text { Mean [SD] } \\
\text { (Number of Respondents) }\end{array}$ \\
\hline Unique consults/year & $1,031.5[556.5](22)$ \\
\hline Length of stay in days & $10[5.2](13)$ \\
\hline Number of visits/patient & $4.2[4.1](18)$ \\
\hline $\begin{array}{l}\text { Total staffing full-time } \\
\text { equivalent }\end{array}$ & $6.8[5.8](21)$ \\
\hline
\end{tabular}

Advanced practice providers include nurse practitioners, advance practice nurses, and physician assistants. 
Calton et al

Table 3. Palliative Care Clinic Characteristics

\begin{tabular}{|c|c|}
\hline Characteristic & $\begin{array}{l}\% \text { Answered Yes } \\
\text { (No. of Respondents) }\end{array}$ \\
\hline \multicolumn{2}{|l|}{ Clinic model } \\
\hline Comanagement & $85.7(18 / 21)$ \\
\hline Consultative & $47.6(10 / 21)$ \\
\hline Other & $14.3(3 / 21)$ \\
\hline $\begin{array}{l}\text { PC embedded in oncology } \\
\text { clinics (vs free-standing) }\end{array}$ & $52(11 / 21)$ \\
\hline \multicolumn{2}{|c|}{ New patient appointment length } \\
\hline $15-30 \mathrm{~min}$ & $0(0 / 21)$ \\
\hline $45 \mathrm{~min}$ & $5(1 / 21)$ \\
\hline $60 \mathrm{~min}$ & $76(16 / 21)$ \\
\hline $75 \mathrm{~min}$ & $10(2 / 21)$ \\
\hline $90 \mathrm{~min}$ & $5(1 / 21)$ \\
\hline Other & $5(1 / 21)$ \\
\hline \multicolumn{2}{|c|}{ Outpatient follow-up patient appointment length } \\
\hline $15 \min$ & $0(0 / 21)$ \\
\hline $30 \mathrm{~min}$ & $71.4(15 / 21)$ \\
\hline $45 \mathrm{~min}$ & $14.3(3 / 21)$ \\
\hline $60 \mathrm{~min}$ & $4.8(1 / 21)$ \\
\hline Other & $9.5(2 / 21)$ \\
\hline Process Measure & $\begin{array}{l}\text { Mean [SD or range] } \\
\text { (Number of } \\
\text { Respondents) }\end{array}$ \\
\hline Unique consults/year & $468.8[214.5](21)$ \\
\hline Number of visits/patient & $4.1[2.5](18)$ \\
\hline $\begin{array}{l}\text { Wait time for new } \\
\text { referrals }\end{array}$ & 16.5 [range, $1.5-90 \mathrm{~d}$ ] (19) \\
\hline $\begin{array}{l}\text { Total staffing full-time } \\
\text { equivalent }\end{array}$ & $3.3(2.5)$ \\
\hline
\end{tabular}

Advanced practice providers include nurse practitioners, advance practice nurses, and physician assistants.

and follow-up with APPs). Most (76\%) new patient clinic appointments were 60 minutes in length and most ( $71 \%$ ) follow-up patient appointments were 30 minutes in length. Average wait time for new referrals was $17+/-21$ days.

An average of $1.3+/-0.6$ FTEs staffed the inpatient $\mathrm{PC}$ or hospice units ( 3 programs reporting). A total of 4 of the 7 programs that reported inpatient $\mathrm{PC}$ or hospice units provided information on number of consults per year. The average number of unique consults per year was $397+/-285$, with a short length of stay $(5+/-2$ days $)$. A total of 3 of 5 home-based PC programs reported staffing data. Home-based/mobile PC programs were staffed by an average of $1.7+/-2$ FTEs. The average number of unique consults per year was $114+/-9$. There was insufficient data to accurately report wait times.

Most (61\%) inpatient PC consultation programs and approximately half (47\%) of clinic-based PC programs reported productivity expectations (typically relative value unit [RVU]-based). Productivity expectations were less common among inpatient PC/hospice units (25\%) and home-based PC programs (20\%).

\section{Research, Quality Improvement, and Education}

Data collection and review of PC program outcomes were variable (Table 4). All institutions collected data on PC program utilization. Approximately onethird of PC programs reported being directed by their institutions to impact specific health care utilization and Quality Oncology Practice Initiative (QOPI) outcomes. Half or fewer programs reported access to various health care utilization metrics at their institutions. Fewer than one-third (29\%) of institutions reported any funding for their PC programs and/or providers to conduct research.

Most (68\%, $\mathrm{n}=15)$ institutions compared their PC programs with national guidelines. In order of prevalence, the most frequently cited guidelines included those from the National Quality Form, Center to Advance Palliative Care (CAPC), NCCN, and QOPI.

A total of $77 \%$ of programs have a PC fellowship associated with their institution. Fellowships were established from 1997 to 2014, with 4 of the 17 fellowships established as recently as 2014. The number of PC fellows rotating in the institutions' PC programs was variable, with most institutions reporting 1 to 4 fellows, and 3 institutions (14\%) reporting 5 or more fellows. Oncology fellows rotate much less frequently within PC. No oncology fellows rotated in PC in $41 \%$ of institutions, and $23 \%$ reported only one oncology rotator. A total of $41 \%$ of institutions noted some cancer center support to provide primary or "generalist" PC training within their cancer centers.

\section{Discussion}

Our survey provides current information on the availability, structure, and basic quality of PC services within NCCN Member Institutions. Inpatient PC services were universal among these institutions and outpatient clinic services were nearly so. Dedicated PC units and home-based services were much 
NCCN Palliative Care Survey

\begin{tabular}{|c|c|}
\hline & $\begin{array}{l}\% \text { Answered Yes } \\
\text { (Number of Respondents) }\end{array}$ \\
\hline \multicolumn{2}{|l|}{ Palliative care has routine access to cancer center's data elements } \\
\hline Hospital 30-day readmission rate for cancer-related admissions & $50(10 / 20)$ \\
\hline $\begin{array}{l}\text { Rate of cancer center patient death in hospital (defined as the proportion of all patients } \\
\text { with cancer decedents who die in the hospital) }\end{array}$ & $50(10 / 20)$ \\
\hline Average length of stay for inpatient patients with cancer & $50(10 / 20)$ \\
\hline Percentage of patients receiving chemotherapy within last 2 weeks of life & $30(6 / 20)$ \\
\hline Percent of discharges to hospice with hospice length of stay less than 3 days & $30(6 / 20)$ \\
\hline Percentage of patients with advanced directive documented in the EMR & $20(4 / 20)$ \\
\hline \multicolumn{2}{|l|}{ Palliative care directed by cancer center to impact outcome } \\
\hline Percentage of patients with advanced directive documented in the EMR & $55(11 / 20)$ \\
\hline Hospital 30-day readmission rate for cancer-related admissions & $35(7 / 20)$ \\
\hline Average length of stay for inpatient patients with cancer & $35(7 / 20)$ \\
\hline Percentage of patients receiving chemotherapy within last 2 weeks of life & $35(7 / 20)$ \\
\hline Percent of discharges to hospice with hospice length of stay less than 3 days & $30(6 / 20)$ \\
\hline $\begin{array}{l}\text { Rate of cancer center patient death in hospital (defined as the proportion of all patients } \\
\text { with cancer decedents who die in the hospital) }\end{array}$ & $30(6 / 20)$ \\
\hline \multicolumn{2}{|l|}{ Palliative care program-collected data elements } \\
\hline Program utilization/number referrals & $100(21 / 21)$ \\
\hline Patient and/or family satisfaction & $47.6(10 / 21)$ \\
\hline Patient utilization outcomes & $33.3(7 / 21)$ \\
\hline Patient clinical outcomes & $28.6(6 / 21)$ \\
\hline Referrer satisfaction & $23.8(5 / 21)$ \\
\hline Other & $4.8(1 / 21)$ \\
\hline
\end{tabular}

Abbreviation: EMR, electronic medical record.

less common. The PC services at these cancer centers typically used a comanagement model, seeing primarily patients with solid tumors. Referrals were typically ad hoc rather than triggered by an objective measure of need. Staffing was typically interdisciplinary with inpatient teams seeing, on average, 151.8 consults per FTE per year, and clinics seeing 142.1 new patients per FTE per year. There was some variability in whether and how programs collect data on their services and whether, and which, national guidelines they follow. Educational services were limited, with relatively limited PC training for oncology fellows and limited primary PC educational activity.

The prior study by Hui et al, ${ }^{12}$ which investigated availability and integration of PC services among $\mathrm{NCI}$-designated and non-NCI cancer centers, provides the closest comparison to our data from NCCN Member Institutions. Keeping in mind potential differences between these institutions, it does appear that, compared with the data reported by Hui et al in
2010, the penetration of PC in cancer centers is likely increasing nationally, including in the outpatient setting. Most (91\%) of the institutions in our study reported having an outpatient $\mathrm{PC}$ clinic. This percentage is in contrast to the $22 \%$ and $59 \%$ of US non-NCI and NCI cancer centers, respectively, reporting PC clinics in 2010. The number of patients seen by PC also appears to be increasing. NCI-designated cancer centers reported an average of 168 outpatient clinic PC referrals annually in 2010 versus 469 in our study. $\mathrm{NCI}$-designated cancer centers reported an average of 576 inpatient PC consults annually in 2010 versus 1,032 in our study. The availability of inpatient PC and hospice units does not appear to have changed significantly since 2010 (32\% in our study vs 30\% for NCI-designated cancer centers). The number of PC physicians on staff was higher in our survey (mean of 4 FTEs) versus a median of 1 FTE in the study by Hui et al. ${ }^{12}$ We lack sufficient data to compare nonphysician staffing between the studies. 
The next frontier for expansion of PC services at cancer centers, particularly for the most vulnerable patients, is likely home-based PC. ${ }^{25}$ Only 5 of the 22 NCCN Member Institutions reported a home-based PC program. We were unable to accurately characterize these programs given limited reported data. Additional research is needed to elucidate these programs' characteristics and home-based PC nationally.

Despite increased availability, demand for PC services continues to outpace supply. A striking $80 \%$ of surveyed institutions reported insufficient PC capacity to meet demand. This deficit is manifested by the long wait times reported for new patient PC clinic visits $(17+/-21$ days $)$. The capacity shortfall is particularly concerning in light of the severity of illness and symptom burden of the cancer population. Financial limitations are a major cause of constricted capacity. In a study of European cancer centers, Davis et $\mathrm{al}^{26}$ cited key barriers to PC, including budget constraints (or priorities), lack of trained personnel, and perceived poor reimbursement for services. Our study found that most programs continue to be supported primarily by fee-for-service reimbursement and institutional support. In the programs surveyed, risk-based reimbursement methodologies were infrequently used to finance PC programs. Strategies to engage payers to support PC services may help remedy program expansion limitations.

In addition to financial limitations, many institutions $(43 \%)$ cited inadequate PC staffing as a significant barrier to provision of PC. Fortunately, the number of PC physician fellowships appears to be increasing. A total of $77 \%$ of institutions surveyed reported the presence of a PC fellowship versus $40 \%$ of NCI-designated cancer centers and $17 \%$ of nonNCI cancer centers in 2010. ${ }^{12}$ Further elucidation of the characteristics of these fellowship programs and interprofessional training opportunities are needed.

Our study results highlight the need for additional non-PC provider training in primary or "generalist" PC. A recent Delphi study of PC-oncology integration experts identified 13 major criteria that would serve as markers of successful PC-oncology integration. ${ }^{27}$ Of these major criteria, 4 related specifically to education, highlighting the critical role PC education should play in caring for patients with cancer. These 4 criteria were: PC didactic curriculum for oncology fellows, continuing medical education in PC for attending oncologists, combing
PC and oncology educational activities for fellows, and oncology fellow rotation on PC services. In our study, $40 \%$ of programs report no oncology fellow participation in PC services. In addition, only $41 \%$ of programs reported support for primary PC education (the details of the type of support is unknown). Taken together, these data highlight the need for the investment in primary PC education to effectively meet the PC needs of patients with cancer, and further integration of the PC and oncology fields.

Triggered referrals (ie, mandated PC referrals based on screening criteria such as disease status, symptom burden, and patient or caregiver characteristics) were not common. Only 14\% of inpatient consultation programs and $21 \%$ of PC clinics reported using trigger criteria to target patients for PC. Potential explanations for this include current workforce limitations, implementation complexities, and the lack of standardized and validated criteria to trigger a referral. Several organizations, including CAPC and NCCN, have proposed screening criteria for PC involvement. ${ }^{28,29}$ However, few tools have been validated or assessed for feasibility. ${ }^{30} \mathrm{~A}$ recent study found that only $10 \%$ of NCCN Member Institutions used any of the available NCCN Clinical Practice Guidelines in Oncology for Palliative Care to formally screen patients for PC, and of these identified patients, only $60 \%$ were ultimately referred to a PC specialist. ${ }^{31}$ Given current workforce issues, further evaluation of PC screening tools and trigger criteria are needed to ensure provision of earlier specialty-level PC services for patients most in need.

Consistent with previously published data, PC referrals for hematologic malignancy patients in our study were disproportionately low. ${ }^{32}$ Approximately $50 \%$ of programs reported that more than $75 \%$ of their referrals were for patients with solid tumors (as opposed to hematologic malignancies). LeBlanc et $\mathrm{al}^{33}$ found that, compared with solid tumor oncologists, hematologic oncologists were more likely to view $\mathrm{PC}$ as end of life care and antithetical to cancer treatment. Further education and partnerships with hematologic oncologists are key to ensuring that these patients have access to specialty-level PC services.

Our study reinforces the need for ongoing efforts to align PC data collection and quality assurance measures nationally. Among NCCN Member Institutions, the quantity and type of PC data collected are variable. Similar diversity is found in programs' 
selection of national PC quality guidelines. Streamlining program evaluation and quality improvement processes via participation in quality improvement collaboratives, such as the Palliative Care Quality Network, ${ }^{34}$ and use of the Quality Data Collection Tool for Palliative Care ${ }^{35}$ will prove helpful.

Our study had several limitations. We surveyed a small number of cancer centers, all of which were NCCN Member Institutions. This could limit the external generalizability of our results. Currently, there is no standardized method of data collection among the programs surveyed. Therefore, some of the data could have been inaccurate or biased, depending on the data available to each PC program and how the survey questions were interpreted. Although we present mean data, the presence of large standard deviations indicates that there is wide range in these data and some outliers. This variation suggests ongoing work must continue to develop appropriate benchmarks, particularly for staffing among PC services in cancer centers.

This survey contributes important and timely information to the fields of oncology and PC. Consistent with the call to integrate PC into the care of patients with advanced cancer, there has been an increase in the availability of PC services, especially in hospital and clinic settings. Unfortunately, homebased services are lacking. Moreover, despite documented growth, specialty PC services in US cancer centers are still insufficient to meet demand. Moving away from fee-for-service reimbursement models to newer models that align clinical goals and financial incentives may help meet these challenges. Providing all clinicians with training in primary PC skills and investing in data collection to measure outcomes and assess value will be essential to improving the care of all patients with advanced cancer.

\section{Acknowledgments}

The authors give many thanks to the NCCN Best Practices Committee for providing administrative and technical support on this project. The authors offer a special thanks to Jessica Sugalski, Lisa Kimbro, and Jean Iannarelli with the NCCN BPC. The authors also wish to thank the NCCN Palliative Care Survey Development Team (eAppendix 1) for their assistance in developing and piloting the survey.

\section{References}

1. Rabow M, Kvale E, Barbour L, et al. Moving upstream: a review of the evidence of the impact of outpatient palliative care. J Palliat Med 2013;16:1540-1549.

2. Temel JS, Greer JA, Muzikansky A, et al. Early palliative care for patients with metastatic non-small-cell lung cancer. N Engl J Med 2010;363:733742 .

3. Bakitas MA, Tosteson TD, Li Z, et al. Early versus delayed initiation of concurrent palliative oncology care: patient outcomes in the ENABLE III randomized controlled trial. J Clin Oncol 2015;33:1438-1445.

4. Zimmermann C, Swami N, Krzyzanowska M, et al. Early palliative care for patients with advanced cancer: a cluster-randomised controlled trial. Lancet 2014;383:1721-1730.

5. Scibetta C, Kerr K, McGuire J, Rabow MW. The costs of waiting: implications of the timing of palliative care consultation among a cohort of decedents at a comprehensive cancer center. J Palliat Med 2016;19:69-75.

6. Bruera E, Hui D. Conceptual models for integrating palliative care at cancer centers. J Palliat Med 2012;15:1261-1269.

7. Smith TJ, Temin S, Alesi ER, et al. American Society of Clinical Oncology provisional clinical opinion: the integration of palliative care into standard oncology care. J Clin Oncol 2012;30:880-887.

8. American College of Surgeons. New CoC Accreditation Standards Gain Strong Support. Available at: https://www.facs.org/media/pressreleases/2011/coc-standards0811. Accessed December 1, 2015.

9. Institute of Medicine. Dying in America: Improving Quality and Honoring Individual Preferences Near the End of Life. Washington, DC: The National Academies Press; 2015. Available at: http://www.iom.edu/ Reports/2014/Dying-In-America-Improving-Quality-and-HonoringIndividual-Preferences-Near-the-End-of-Life.aspx. Accessed December 1, 2015.

10. Foley K, Gelband H, eds. National Cancer Policy Board: Improving Palliative Care for Cancer. In: Washington, DC: The National Academies Press; 2001.

11. Levy M, Smith $T$, Alvarez-Perez A, et al. NCCN Clinical Practice Guidelines in Oncology: Palliative Care. Version 1.2016. Available at: NCCN.org. Accessed December 1, 2015.

12. Hui D, Elsayem A, De la Cruz M, et al. Availability and integration of palliative care at US cancer centers. JAMA 2010;303:1054-1061.

13. Rabow MW, Smith AK, Braun JL, Weissman DE. Outpatient palliative care practices. Arch Intern Med 2010;170:654-655.

14. Smith AK, Thai JN, Bakitas MA, et al. The diverse landscape of palliative care clinics. J Palliat Med 2013;16:661-668.

15. Rabow MW, O'Riordan DL, Pantilat SZ. A statewide survey of adult and pediatric outpatient palliative care services. J Palliat Med 2014;17:13111316.

16. Lupu D; American Academy of Hospice and Palliative Medicine Workforce Task Force. Estimate of current hospice and palliative medicine physician workforce shortage. J Pain Symptom Manage 2010;40:899-911.

17. California Healthcare Foundation. Uneven Terrain: Mapping Palliative Care Need and Supply in California. Available at: http://www.chcf.org/ publications/2015/02/palliative-care-data. Accessed December 1, 2015.

18. Hui D, Kim SH, Kwon JH, et al. Access to palliative care among patients treated at a comprehensive cancer center. Oncologist 2012;17:1574-1580.

19. American Society of Clinical Oncolgy. Quality Oncology Practice Initiative (QOPI). Available at: http://www.instituteforquality.org/qualityoncology-practice-initiative-qopi. Accessed December 1, 2015.

20. American Academy of Hospice and Palliative Medicine. Measuring What Matters. Available at: http://aahpm.org/quality/measuring-what-matters. Accessed December 1, 2015.

21. Palliative Care Endorsed Measures. National Quality Forum Web site. Available at: https://www.qualityforum.org/QPS/QPSTool.aspx?p=783. Accessed December 1, 2015.

22. Yennurajalingam $S$, Urbauer DL, Casper KL, et al. Impact of a palliative care consultation team on cancer-related symptoms in advanced patients with cancer referred to an outpatient supportive care clinic. J Pain Symptom Manage 2011;41:49-56.

23. Bischoff $\mathrm{K}$, Weinberg V, Rabow MW. Palliative and oncologic comanagement: symptom management for outpatients with cancer. Support Care Cancer 2013;21:3031-3037.

24. Hui D, Kim SH, Roquemore J, et al. Impact of timing and setting of palliative care referral on quality of end-of-life care in patients with cancer. Cancer 2014;120:1743-1749. 
25. Kamal AH, Currow DC, Ritchie CS, et al. Community-based palliative care: the natural evolution for palliative care delivery in the U.S. J Pain Symptom Manage 2013;46:254-264.

26. Davis MP, Strasser F, Cherny N. How well is palliative care integrated into cancer care? A MASCC, ESMO, and EAPC Project. Support Care Cancer 2015;23:2677-2685.

27. Hui D, Bansal S, Strasser F, et al. Indicators of integration of oncology and palliative care programs: an international consensus. Ann Oncol 2015;26:1953-1959.

28. Levy MH, Smith T, Alvarez-Perez A, et al. Palliative Care, Version 1.2014. Featured updates to the NCCN Guidelines. J Natl Compr Canc Netw 2014;12:1379-1388.

29. Weissman DE, Meier DE. Identifying patients in need of a palliative care assessment in the hospital setting: a consensus report from the Center to Advance Palliative Care. J Palliat Med 2011;14:17-23.
30. Glare PA, Chow K. Validation of a simple screening tool for identifying unmet palliative care needs in patients with cancer [published online ahead of print November 12, 2014]. J Oncol Pract, pii: JOP.2014.001487.

31. Albizu-Rivera A, Portman DG, Thirlwell S, et al. Implementation of NCCN Palliative Care Guidelines by member institutions. Support Care Cancer 2016;24:929-932.

32. LeBlanc TW. In the sandbox: palliative care and hematologic malignancies. J Community Support Oncol 2014;12:44-45.

33. LeBlanc TW, O’Donnell JD, Crowley-Matoka M, et al. Perceptions of palliative care among hematologic malignancy specialists: a mixedmethods study. J Oncol Pract 2015;11:e230-238.

34. Pantilat SZ, Bragg AR, O'Riordan DL, et al. Palliative Care Quality Network: toward quality improvement in palliative care [abstract]. Presented at the 20th International Congress of Palliiative Care; September 9-12, 2014; Montreal, Canada.

35. Kamal AH, Kavalieratos D, Bull J, et al. Usability and acceptability of the QDACT-PC, an electronic point-of-care system for standardized quality monitoring in palliative care. J Pain Symptom Manage 2015;50:615-621.

\section{See JNCCN.org for supplemental online content.}

